\title{
Modelling field scale water partitioning using on-site observations in sub-Saharan rainfed agriculture
}

\author{
H. Makurira ${ }^{1,2,3}$, H. H. G. Savenije ${ }^{2,3}$, and S. Uhlenbrook ${ }^{2,3}$ \\ ${ }^{1}$ Dept. of Civil Engineering, University of Zimbabwe. P.O. Box MP 167, Mt Pleasant, Harare, Zimbabwe \\ ${ }^{2}$ Water Resources Section, Delft University of Technology, P.O. Box 5048, 2600 GA Delft, The Netherlands \\ ${ }^{3}$ UNESCO-IHE, Institute for Water Education, P.O. Box 3015, 2601 DA Delft, The Netherlands
}

Received: 13 July 2009 - Published in Hydrol. Earth Syst. Sci. Discuss.: 20 August 2009

Revised: 4 March 2010 - Accepted: 18 March 2010 - Published: 6 April 2010

\begin{abstract}
Smallholder rainfed farming systems generally realise sub-optimal crop yields which are largely attributed to dry spell occurrences during crop growth stages. However, through the introduction of appropriate farming practices, it is possible to substantially increase yield levels even with little and highly variable rainfall. The presented results follow research conducted in the Makanya catchment in northern Tanzania where gross rainfall amounts to less than $400 \mathrm{~mm} / \mathrm{season}$ which is insufficient to support staple food crops (e.g. maize). The yields from farming system innovations (SIs), which are basically alternative cultivation techniques, are compared against traditional farming practices. The SIs tested in this research are runoff harvesting used in combination with in-field trenches and soil bunds (fanya juus). These SIs aim to reduce soil and nutrient loss from the field and, more importantly, promote in-field infiltration and water retention. Water balance components have been observed in order to study water partitioning processes for the "with" and "without" SI scenarios. Based on rainfall, soil evaporation, transpiration, runoff and soil moisture measurements, a water balance model has been developed to simulate soil moisture variations over the growing season. Simulation results show that, during the field trials, the average productive transpiration flow ranged between $1.1-1.4 \mathrm{~mm} \mathrm{~d}^{-1}$ in the trial plots compared to $0.7-1.0 \mathrm{~mm} \mathrm{~d}^{-1}$ under traditional tillage practice. Productive transpiration processes accounted for $23-29 \%$ while losses to deep percolation accounted for $33-48 \%$ of the available water. The field system has been successfully modelled using the spreadsheet-based water balance 1-D model. Conclusions from the research
\end{abstract}

Correspondence to: $\mathrm{H}$. Makurira (makurira@eng.uz.ac.zw) are that the SIs that were tested are effective in enhancing soil moisture retention at field scale and that diversions allow crop growth moisture conditions to be attained with early rains. From the partitioning analysis, it is also concluded that there is more scope for efficient utilisation of the diverted runoff water if storage structures could be installed to minimise runoff and deep percolation and, hence, regulate water flow to the root zone when required.

\section{Introduction}

The impact of climate variability and climate change is felt differently by different sectors and at different scales. In relation to food security, the effect of dry spell occurrences during critical cropping seasons as a result of erratic rainfall patterns may result in severe yield reductions in farming systems (Barron et al., 2003). In semi-arid environments, water is a major constraint to agricultural production (cf. Ngigi, 2003). This implies that farmers need to improve on current yield levels by adopting innovative rainwater harvesting and soil water conservation techniques (Kosgei, 2009; Mupangwa et al., 2006; Rockström, 2003; Rockström et al., 2004). The big challenge now is that the current levels are generally too low for existing food demands and average less than $1 \mathrm{tha}^{-1}$ for maize in some semi-arid environments (Bhatt et al., 2006; Rockström et al., 2004). Irrigation is perceived to be the solution to the challenge of dry spells. However, the large investments required to set up irrigation schemes means that, without external assistance through the support of governments and donors, many vulnerable communities will still rely on rainfed farming for their subsistence.

Published by Copernicus Publications on behalf of the European Geosciences Union. 
Rainwater harvesting systems are not widely implemented in Eastern and Southern Africa despite numerous research findings recommending the adoption of rainwater harvesting as a solution to the challenge of mid-season dry spell occurrences. The few micro-dams and ponds identified in arid and semi-arid areas are generally poorly located for effective irrigation or for use as multi-purpose reservoirs (Rockström, 2000). On the other hand, large scale and seemingly organised irrigation schemes require substantial investment costs and tend to benefit only few participating members. This means that the majority of the population, who, incidentally, rely mostly on rainfed subsistence agriculture, need to resort to simple and innovative agricultural techniques for soil moisture retention in order to cope with the mid-season dry spells. In the past, when more unoccupied land was available, communities practiced shifting agriculture by relocating to less populated and more fertile land resources (cf. Fischer, 2008). Nowadays, local solutions which aim to optimize available resources are required. Such solutions exist through the adoption of more efficient system innovations (SIs) (Ngigi et al., 2007; Rockström et al., 2001; Temesgen et al., 2007) and such SIs include conservation tillage, rainwater harvesting, the promotion of water retention at field scale (e.g. fanya juus), the development of more communitydriven irrigation schemes, use of drought resistant seed varieties, adoption of more appropriate crops for different environments and, better farm management (e.g. timing of operations, application of pesticides and insecticides, addition of soil nutrients through fertilisers and animal manure). However, the adoption of these solutions is not often guaranteed as social preferences and traditional practices tend to influence community behaviour.

Rainfall variability in sub-Saharan Africa is very high with a difference of as much as $60 \mathrm{~mm} \mathrm{~d}^{-1}$ in rainfall recorded within a spatial distance of $10 \mathrm{~km}$ (Mul et al., 2009). The increasing climate variability has seen an upward trend in dry spells in some parts of semi-arid Sub-Saharan Africa (Enfors and Gordon, 2007; Fischer, 2008). It is becoming a bigger challenge to improve or, at least, maintain the current crop yield levels under the existing climate regime and traditional farming practices. Instead, smallholder farmers, who constitute the greater proportion of the population, will increasingly rely on food imports as a result of these seasonal low yields and their vulnearbility to droughts and dry spells. Given these challenges, it is important to assist smallholder farmers to break the poverty cycle by relying less on food imports and encouraging them to adopt more efficient farming techniques which result in improved crop productivity under harsh climatic challenges (Enfors and Gordon, 2008). A number of improved agricultural techniques have been tested throughout the region with promises of success but adoption by farmers has not been encouraging (Ngigi et al., 2005). One possible explanation for the poor adoption by farmers could be that scientists themselves do not have full understanding of the water partitioning processes at field scale to explain the hydrological processes prevailing when improved techniques are applied.

However, it seems very well possible to improve crop productivity even under these challenging conditions. A variety of SI options exist which, if applied, help to achieve improved results. The level of success for any SI that can be considered largely depends on site conditions. An example of more efficient techniques is the fanya juи cultivation method which, if used in combination with runoff harvesting, results in improved soil moisture availability. Fanya juus are basically trenches constructed along contour lines within the cultivated field and are spaced as dictated by the slope. Soil from the excavated trenches is deposited upslope, so as to create a bund for water retention. The fanya juus have been researched before as soil conservation structures (Gichuki, 2000; Mwangi et al., 2001; Tenge et al., 2005) but their hydrological functioning on cropping systems have not been investigated in detail.

The objectives of the research presented in this paper are to (i) use observed on-site data to model soil moisture dynamics for the tested "improved" farming techniques, and hence (ii) quantify water partitioning at the field scale to assess the impact of the applied techniques with regards their hydrological functioning.

\section{Materials and methods}

\subsection{Research site}

The research has been conducted in the Makanya catchment in northern Tanzania (Fig. 1) at two sites. These sites, Site 1 (Iddi farm) and Site 2 (Walter farm) are located in the Mwembe village within the Makanya catchment. The Makanya catchment is part of the Pangani Basin and covers a catchment area of about $300 \mathrm{~km}^{2}$ (Mul et al., 2007). The rainfall variability is high and ranges between 400$800 \mathrm{~mm} \mathrm{a}^{-1}$ and is heavily influenced by altitude. Two rainfall seasons are experienced in a year with the long rainfall season (Masika) occurring between March and May while the short rainfall season (Vuli) occurs anytime between October and December. The annual rainfall received is thus split over two agricultural seasons which implies that, on average, seasonal rainfall alone cannot support the common crops grown in the area such as maize, beans and coffee $\mathrm{Mu}-$ tiro et al., 2006). An analysis of the rainfall patterns at a nearby meteorological station suggests a steady mean in the total amount of rainfall received but an increasing trend in dry spell occurrences especially in the Masika season (Enfors and Gordon, 2007).

The local communities in the catchment rely on subsistence agriculture for food production. A variety of soil and water conservation practices is observed within the study area and these include hand-hoeing, terracing, intercropping, rainwater harvesting (particularly flow diversions) 
and irrigation from micro-dams. Groundwater exploitation is low with substantial amounts of surface water infiltrating into the ground and, possibly, draining out of the catchment as sub-surface flow (Mul et al., 2007).

\subsection{Experimental design}

The research has been conducted over four seasons between 2006 and 2007. The research compares current farming practices of hand-hoe cultivation against system innovations (SIs) which basically consist of the application of conservation tillage practices in combination with water harvesting In the research, an ordinary field has been partitioned into strips of about $10 \mathrm{~m}$ width across the field. This spacing is dictated by slope and follows general soil conservation guidelines for the construction of contour ridges which have been generally applied as soil conservation structures in tilled plots. For steeper slopes this spacing is reduced while it increases on flatter terrains. Trenches measuring $50 \mathrm{~m}$ by $50 \mathrm{~m}$ have been dug across the field along the contour line. The soil from the excavations is thrown upslope to form soil bunds just upslope of the trenches. This type of in-field constructions is called the fanya jии technique in East Africa. Runoff generated from storm events has been diverted from adjacent drainage channels such as footpaths and gullies and has been directed into the trenches constructed within the field. The trenches act as temporary storage structures after rainfall and diversion events while the bunds create ponding conditions upslope of the excavated trenches. Infiltration potential is enhanced in the trenches and at the ponding zones as a result of increased residence time of water. In addition, the reduction in runoff velocity within the cultivated field implies an increased potential for deposition of nutrient-rich fine soil within the cultivated plots.

Water balance components necessary for the simulation have been measured on site or determined from empirical relationships.

\subsection{Soil moisture measurements}

To evaluate the effect of different treatment techniques, soil moisture has been measured by use of the time domain reflectometry (TDR) method. Four access tubes have been inserted within the cultivated field using a hand auger to the maximum possible depth. This depth does not normally exceed $1.5 \mathrm{~m}$ in the studied area. Tube A has been placed in the control plot i.e. the section within the same sloping transect file but upslope of the diversions which implies that it measures soil moisture variations which are largely influenced by rainfall events only. The other three tubes have been placed within one cultivated strip but located such that Tube B is closest to the trench, Tube $\mathrm{C}$ in the middle of the cultivated strip and Tube D has been placed at the lower end of the cultivated strip and closest to the bunds. From Fig. 2 it can be seen that Tube B monitors the impact to the root zone of

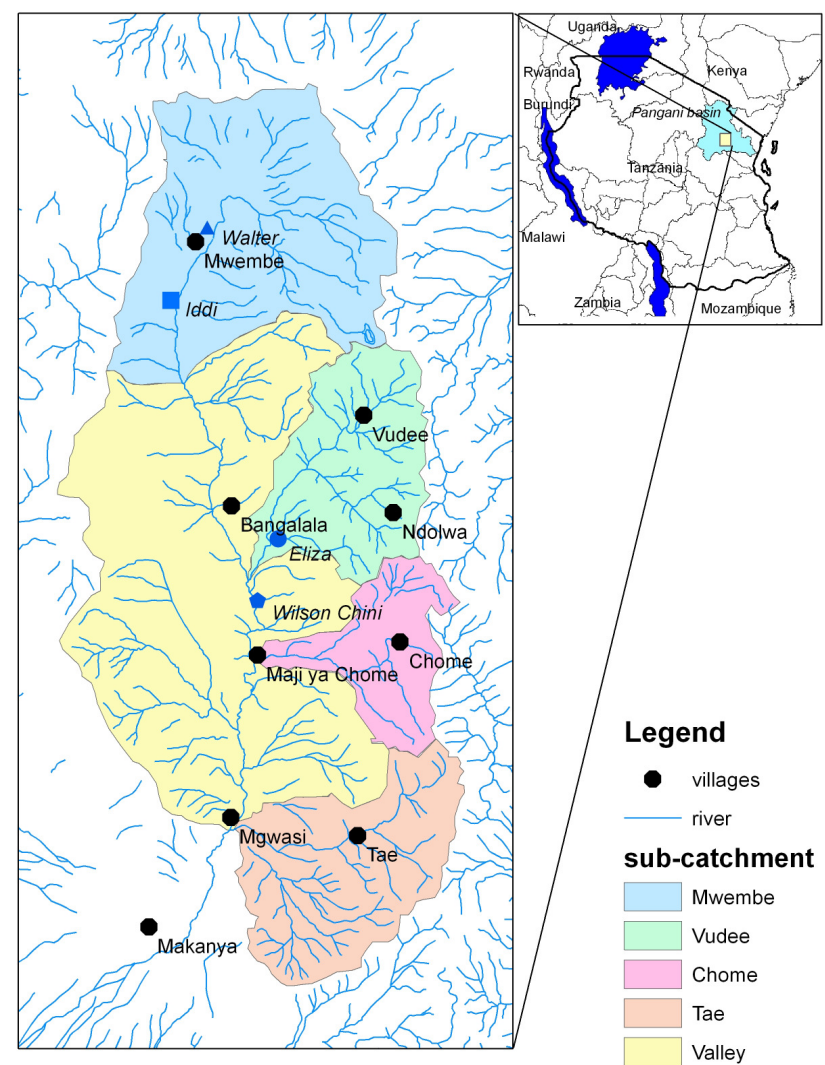

Fig. 1. Location of the study areas in the Mwembe sub-catchment of the Makanya catchment in northern Tanzania.

water stored in the trench while Tube D monitors the effect of ponded water as a result of the soil bund. Tube $\mathrm{C}$ monitors in the moisture distribution across the cultivated strip mainly as a result of direct infiltration and lateral flow from the water that is temporarily stored in the trenches. Soil moisture observations have been made twice a week during the growing season and once in two weeks during the dry season.

Soil moisture has been observed at $10 \mathrm{~cm}$ depth intervals but, since the roots of the studied maize crop in the research area hardly exceeded $50 \mathrm{~cm}$, soil moisture at $30 \mathrm{~cm}$ depth has been taken as a realistic representation of the soil moisture content across the rooting zone.

\subsection{Water balance modelling}

Soil moisture storage has been modelled using a spreadsheet based water balance model (based on Savenije, 1997). The model is based on the water balance equation which is given as:

$\frac{d S_{s}}{d t}+\frac{d S_{u}}{d t}+\frac{d S_{g}}{d t}=P-E_{T}-E_{I}-E_{S}-Q_{g}-Q_{s}$

where (all terms in $\mathrm{mm} \mathrm{d}^{-1}$ ),

$P$ is the precipitation received in the system,

$E_{T}$ is the transpiration, 


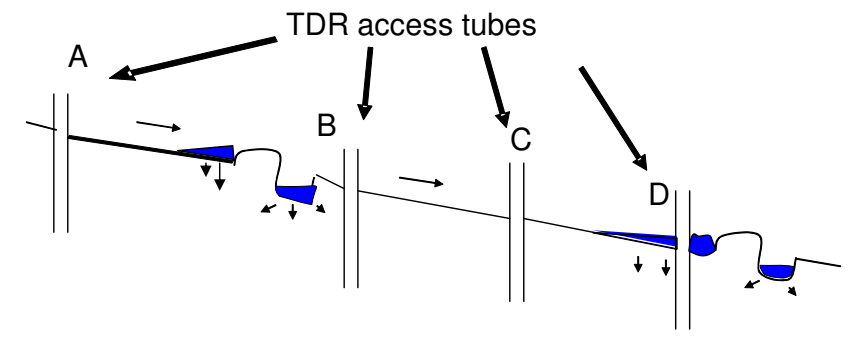

Fig. 2. Schematic of a section of the cultivated field showing TDR access tubes placed to measure soil moisture variation in relation to the location of the trenches and soil bunds (fanya juu constructions).

$E_{I}$ is the evaporation from interception i.e. from canopy cover and soil surface,

$E_{s}$ is the evaporation from the soil,

$Q_{s}$ is the net surface runoff,

$Q_{g}$ is the groundwater runoff,

$\frac{d S_{s}}{d t}$ is the rate of change of surface water storage,

$\frac{d S_{u}}{d t}$ is the rate of change of water storage in the root zone,

$\frac{d S_{g}}{d t}$ is the rate of change of groundwater storage.

The components in the above equation can be determined from direct observations or, alternatively, from empirical relationships.

During the field trials, $P$ and $Q_{s}$ were measured using onsite rain gauges. At the daily time scale used, $\frac{d S_{s}}{d t}$ is considered to be negligible compared to the other fluxes. The transpiration and soil evaporation $\left(E_{T}\right.$ and $\left.E_{S}\right)$, are modelled as a function of the soil moisture $S_{s}$. Groundwater storage and flow $\left(\frac{d S_{g}}{d t}\right.$ and $\left.Q_{g}\right)$ are fed by groundwater recharge which occurs when the soil moisture within the root zone exceeds field capacity. This study concentrates on the root zone hence these deeper groundwater processes can be ignored. The interception, $E_{I}$, is determined on the basis of the daily rainfall following the method by De Groen and Savenije (2006). As a result, the soil moisture storage in the unsaturated zone, $S_{u}$, remains the only unknown in the equation. The simulated soil moisture storage is subsequently compared with the observed soil moisture variations. This process is only analysed in the vertical direction hence the model is defined as a 1-D model.

\section{Estimation of model inputs}

The modelling approach for evaporation is based on the FAO-56 dual crop coefficient method which separates evaporation and transpiration processes Fig. 3 shows a flow chart illustrating the adapted method.

Input parameters have been estimated according to the processes explained below (Allen et al., 1998, 2005; Savenije, 1997; Temesgen et al., 2007).

\section{Input parameters obtained from direct observations}

- Precipitation $(P)$ has been measured daily using rain gauges installed on site.

- Surface runoff contribution $\left(Q_{s}\right)$ has been directed onto the experimental sites through one inlet point and has been allowed out through one exit point. Tipping bucket loggers have been installed at these points to measure surface flow into and out of the study plot. The difference between inflow and outflow is the net surface flow contribution, $Q_{s}$. Hence, the runoff contribution has been measured continuously.

- Leaf area index $\left(I_{\mathrm{LA}}\right)$ : the Decagon Acupar meter (Decagon Devices Inc., 2004) has been used to measure the leaf area index of the growing maize crop. The equipment measures above canopy and below canopy radiation from which the leaf area index is calculated. Measurements have been taken at all sites on a weekly basis during the long season of 2006.

- Dialy open water evaporation, $\left(E_{o}\right)$ has been measured using a Class A pan located at a nearby meteorological station. The evaporation has been determined from the measured volume required to top up the water level at a set time every day.

\section{Input parameters obtained from literature}

- Interception $\left(E_{I}\right)$ is estimated based on De Groen and Savenije (2006) where all the rainfall received is intercepted until a certain threshold value of precipitation, $D$, is reached beyond which the excess precipitation becomes available for infiltration and runoff.

$E_{I}=\min (P, D)$

where (all in $\mathrm{mm} \mathrm{d}^{-1}$ )

$E_{I}$ evaporation from interception,

$P$ daily rainfall

$D$ interception threshold determined by calibration (ranges between $2-5 \mathrm{~mm} \mathrm{~d}^{-1}$ (De Groen and Savenije, 2006)

- Crop coefficients $\left(k_{c}\right)$ have been obtained from FAO-56 for evaporation and transpiration are treated separately as shown in Fig. 3.

\section{Derived input parameters}

- The reference evaporation $\left(E_{\text {ref }}\right)$ is estimated from the FAO recommended methods of estimating the total evaporation (soil evaporation, interception and transpiration) (Allen et al., 1998) i.e.

$$
E_{\mathrm{ref}}=E_{o} k_{p}
$$




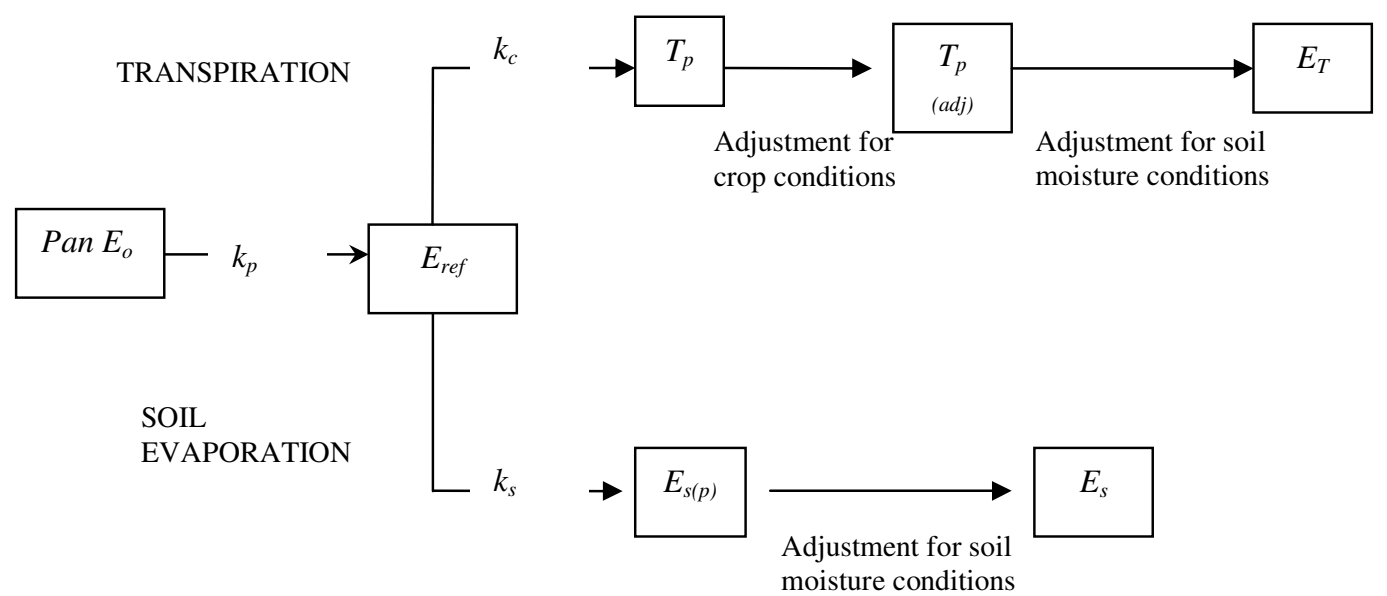

Fig. 3. Flow chart for determining evaporation and transpiration.

$E_{\text {ref }}$ reference evaporation $\left(\mathrm{mm} \mathrm{d}^{-1}\right)$

$E_{o}$ open water evaporation $\left(\mathrm{mm} \mathrm{d}^{-1}\right)$

$k_{p}$ pan coefficient (-), ranges between $0.6-0.8$ for the conditions in study area (according to FAO-56)

- Transpiration

- Potential transpiration, $T_{p}$

A growing crop under optimum conditions transpires at the potential transpiration rate, $T_{p}$. This potential transpiration is related to the reference transpiration by a crop transpiration factor, $k_{c}$, which is a function of the crop type and its development stage.

The potential transpiration for any crop is therefore calculated as

$T_{p}=E_{\text {ref }} k_{c}$

where $T_{p}$ potential transpiration $\left(\mathrm{mm} \mathrm{d}^{-1}\right)$

$k_{c}$ crop factor (-) and ranges between $0.15-1.15$ for the maize crop (according to FAO-56)

Equation (4) applies to a crop growing under ideal conditions. The natural environment necessitates a further adjustment of $k_{c}$ to suit local conditions (Allen, 2000). When there is no moisture stress transpiration is assumed to be related to the leaf area index, $I_{\mathrm{LA}}$, (Temesgen et al., 2007). The modified potential transpiration is hence calculated as

$T_{p, \text { adj }}=\max \left(\left(E_{\mathrm{ref}} k_{c}-E_{I}\right) 0\right) \min \left(1, I_{\mathrm{LA}}\right)$

where $T_{p \text {,adj }}$ adjusted potential transpiration $\left(\mathrm{mm} \mathrm{d}^{-1}\right)$

$I_{\text {LA }}$ leaf area index $\left(\mathrm{m}^{2} \mathrm{~m}^{-2}\right)$

- Actual transpiration from a crop, $E_{T}$

$T_{p}$ described in Eq. 5 assumes unlimited water availability within the root zone. In practice, however, soil moisture varies within the available water content (AWC) range described as the difference between the field capacity $\left(S_{\mathrm{fc}}\right)$ and the permanent wilting point $\left(S_{\mathrm{wp}}\right)$. Potential transpiration occurs between saturated moisture conditions until the moisture content drops to a fraction $p$ (taken as 0.6) of the available soil moisture when stress conditions start to occur. Transpiration stops when the soil moisture level drops to the permanent wilting point. Within the moisture stress range $(1-p)$ $\left(S_{\mathrm{fc}}-S_{\mathrm{wp}}\right)$ transpiration reduces according to proportions dictated by the gradient $k$ which is defined as

$k=\frac{1}{(1-p)\left(S_{\mathrm{fc}}-S_{\mathrm{wp}}\right)}$

where $k$ moisture stress gradient $\left(\mathrm{mm}^{-1}\right)$

$S_{\mathrm{fc}}$ soil moisture at field capacity $(\mathrm{mm})$

$S_{\mathrm{wp}}$ soil moisture at wilting point $(\mathrm{mm})$

$p$ fraction of no moisture stress (-)

The moisture stress factor limiting transpiration can therefore be expressed as

$f_{\mathrm{mt}}=k \min \left(\left(S_{u}-S_{\mathrm{wp}}\right), 1\right)$

where $f_{\mathrm{mt}}$ moisture stress factor (-)

$S_{u}$ soil moisture within the root zone $(\mathrm{mm})$

The actual transpiration, $E_{T}\left(\mathrm{~mm} \mathrm{~d}^{-1}\right)$, is given by the relationship

$E_{T}=T_{p, \text { adj }} f_{\mathrm{mt}}$

- Soil evaporation, $E_{S}$

The energy available at the soil surface is shared between transpiration and direct soil evaporation (Allen, 2000). Where water is in abundance, climatic influences play a less significant role towards transpiration rates 
(Novák et al., 2005). As canopy cover increases, more energy is used for transpiration at the expense of direct soil evaporation. Similar to transpiration, soil evaporation only occurs at the potential rate under ideal conditions including sufficient soil moisture. Whereas transpiration occurs at reduced rates up to the wilting point, the cut-off level for soil evaporation occurs before the wilting point due to capillary forces of the soil matrix.

The soil moisture stress factor can be described by an exponential function involving $S_{u}$ and the maximum water available within the root zone $\left(S_{\max }\right)$ with a reduction scale $b(\mathrm{~mm})$ :

$f_{\mathrm{ms}}=\min \left(\exp \left(\frac{S_{u}-S_{\max }}{b}\right), 1\right)$

where $f_{\mathrm{ms}}$ moisture stress reduction factor (-)

$S_{\max }$ maximum soil moisture in the root zone $(\mathrm{mm})$

$b$ reduction scale $(\mathrm{mm})$

The evaporation from the soil is given by

$E_{s}=\max \left(1-I_{\mathrm{LA}}, 0\right) \max \left(k_{s} E_{\mathrm{ref}}-E_{I}, 0\right) f_{\mathrm{ms}}$

where $E_{s}$ soil evaporation $\left(\mathrm{mm} \mathrm{d}^{-1}\right)$

$k_{s}$ soil evaporation factor (equivalent to crop factor in cropped areas) (-)

In Eq. 10, interception is subtracted from reference evaporation because both are evaporation processes with evaporation from interception occurring immediately after a rainfall event as canopy interception or evaporation from the soil crust.

- Infiltration, $F$, and deep percolation, $R$

At daily time steps, where $\frac{d S_{s}}{d t}$ is considered negligible, the infiltration into the soil $F\left(\mathrm{~mm} \mathrm{~d}^{-1}\right)$ is calculated as

$F=P+Q_{s}-E_{I}$

\section{Calculated model output}

The soil moisture balance at any given time-step $t$, which is also the model output at each time step, is hence calculated as

$\frac{d S_{s}}{d t}=F-E_{T}-E_{s}-R$

where deep percolation, $R\left(\mathrm{~mm} \mathrm{~d}^{-1}\right)$ is calculated as a flow over threshold process which only occurs when the field capacity is exceeded.

$R=\max \left[\frac{S_{u}-S_{\mathrm{fc}}}{k_{R}}, 0\right]$

and $k_{R}(\mathrm{~d})$ isthe maximum number of days during which field capacity can be exceeded after high infiltration events.

\section{Results}

\subsection{Soil moisture observations}

Soil moisture measurements over four seasons (2006-2007) are shown in Fig. 4 and have been used as a measure of the performance of the water balance model. The observed soil moisture shows a clear trend where the tube located on the most downslope part and next to the bund (Tube D) records the highest moisture levels. The control tube (Tube A) records the least moisture levels which are also comparable to the middle tube (Tube C). Tube $\mathrm{B}$ records values in between. This trend is more distinct at Site 1 where the terrain is more gentle and the soils are deeper. Site 2 has steeper slopes and shallower soil depths. The moisture distribution at Site 2 exhibits a similar trend as for Site 1 although the control tube and Tube B appear to respond more quickly to rainfall and diversion events at Site 2. The middle tube, Tube C, also records better response to events at Site 2 than at Site 1 .

\subsection{Soil moisture modelling}

The spreadsheet based water balance model has been constructed as conceptualised above. The model simulates soil moisture at daily time steps. Each simulation calculates the soil moisture for the control and the site under SIs. The main difference between these sites is that the area under SIs benefits from diversion water while the control is strictly rainfed. A rooting depth of $50 \mathrm{~cm}$ is used in the model. The soil properties are assumed to remain constant within the $10 \mathrm{~m}$ width.

The output is plotted in Fig. 4 where the solid lines indicate the simulated soil moisture.

The modelling results show a good agreement with the observed soil moisture for both the control and the portion benefitting from diverted water. The modelled results for diverted flow correspond well with the downslope tube (Tube D), while the simulation with no diversion corresponds well with the control (Tube A). The difference between the control and experimental lines indicates the effect of the SIs which, in this case, is the diversions. The biggest difference occurs at the beginning of the season and is lowest when enough rainfall and infiltration is realised and field capacity conditions are attained. At both sites the simulated flow with diversions shows that the soil reaches field capacity much earlier than the control section at the onset of the rainy season. This is important since it allows the growing season to start earlier.

\subsubsection{Improving model performance}

In Fig. 4, Site 1 shows better agreement between observed and simulated soil moisture levels than Site 2. The simulation (a) of Site 2 shows disagreement especially at the onset of the experiment where simulated values are much higher than the observed. This is explained by the fact that the experimental plot may not have been prepared well enough 

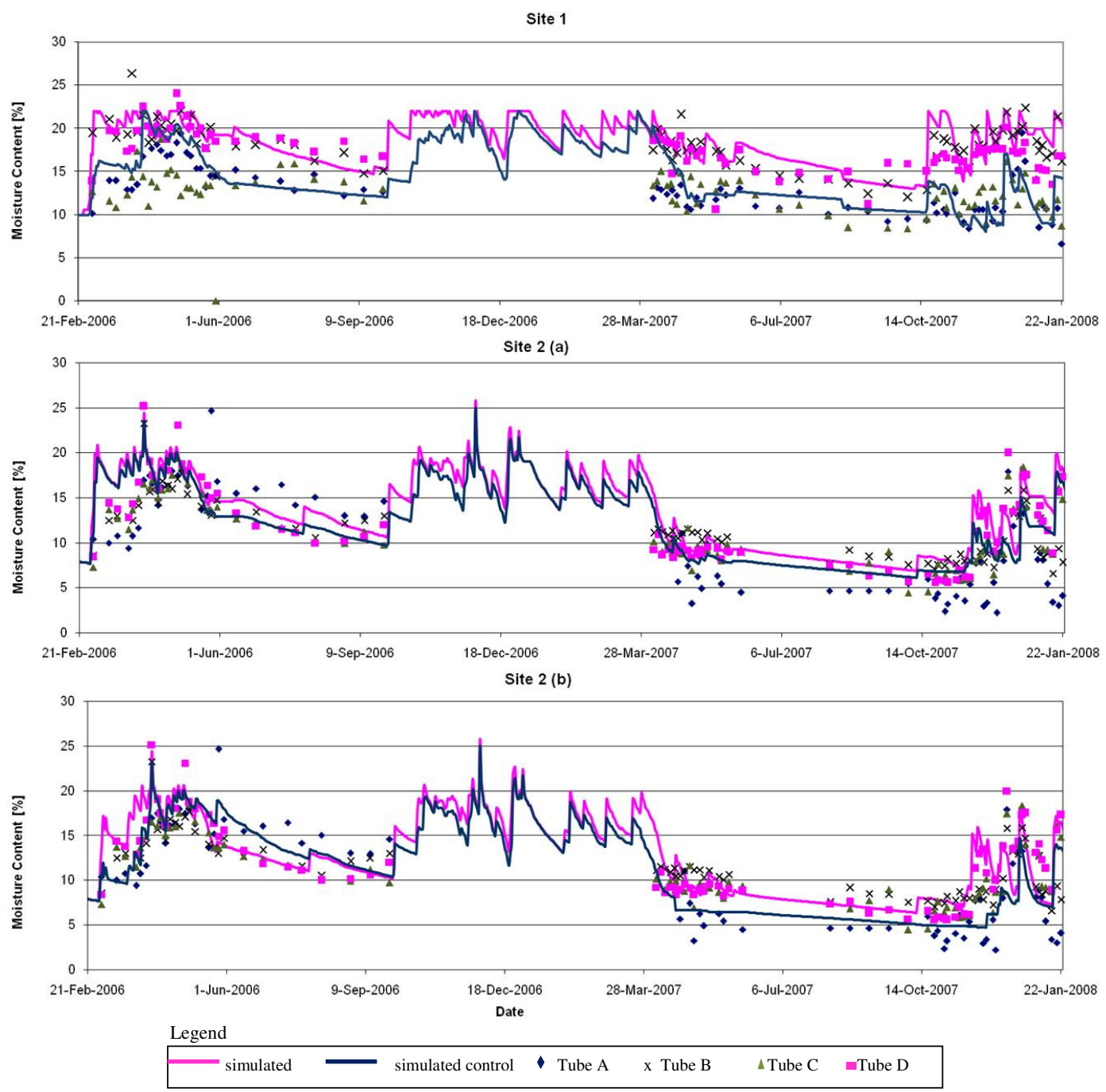

Fig. 4. Model results at different sites compared with observed soil moisture values for Site 1 and Site 2. The graph at Site 2(b) presents an improved simulation than the graph at Site 2(a).

with the top soil still very dry hence less infiltration actually occurred. The model has been improved by lowering the field capacity during the first few days of experimentation thereby restricting infiltration after rainfall events. Thereafter, and for the rest of the season, the control plot records higher moisture levels as it also receives extra water from lateral flows from upslope. Similarly, during the dry season prior to November 2007, a few rainfall events have been observed which were translated into infiltration in the simulation. Consequently, simulated results show higher moisture levels than the observed. However, since the previous rainfall season had recorded extended dry spells towards the end, the soils were in fact much drier hence, again, the rainfall could not practically be translated into infiltration. The model has been corrected by draining this apparent infiltrated water during the dry season.
The improved model output is shown as Site 2 (b) in Fig. 4 and shows a much better correspondence between modelled and observed values.

\subsubsection{Test of model efficiency}

Figure 5 shows a comparison of the modelled and observed results with the graph forced to pass through the origin. All trend lines have slopes close to 1 which is satisfactory. Site 2 (b), which shows the trends after the model improvement described above, reflects an improvement in $R^{2}$ value which reflects more refined simulations. This is also confirmed by the Root Mean Square Error (RMSE) calculation of 3.3 and 1.9 at Site 1 for Tube A and Tube D, respectively. At Site 2, the RMSE decreased from 4.2 to 2.6 for Tube A after the model improvement while it increased from 2.3 to 2.4 for Tube D. This also shows that the model improvement was most efficient in the control plot. 
Site 1 (Tube A)
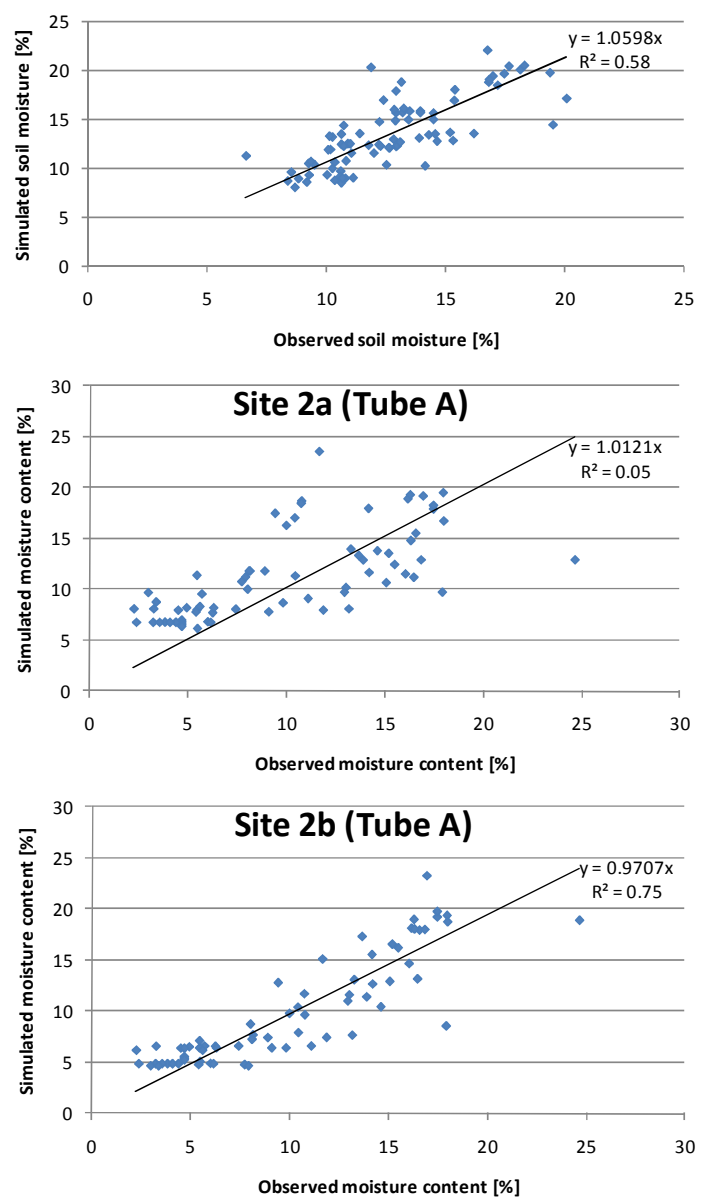

Site 1 (Tube D)
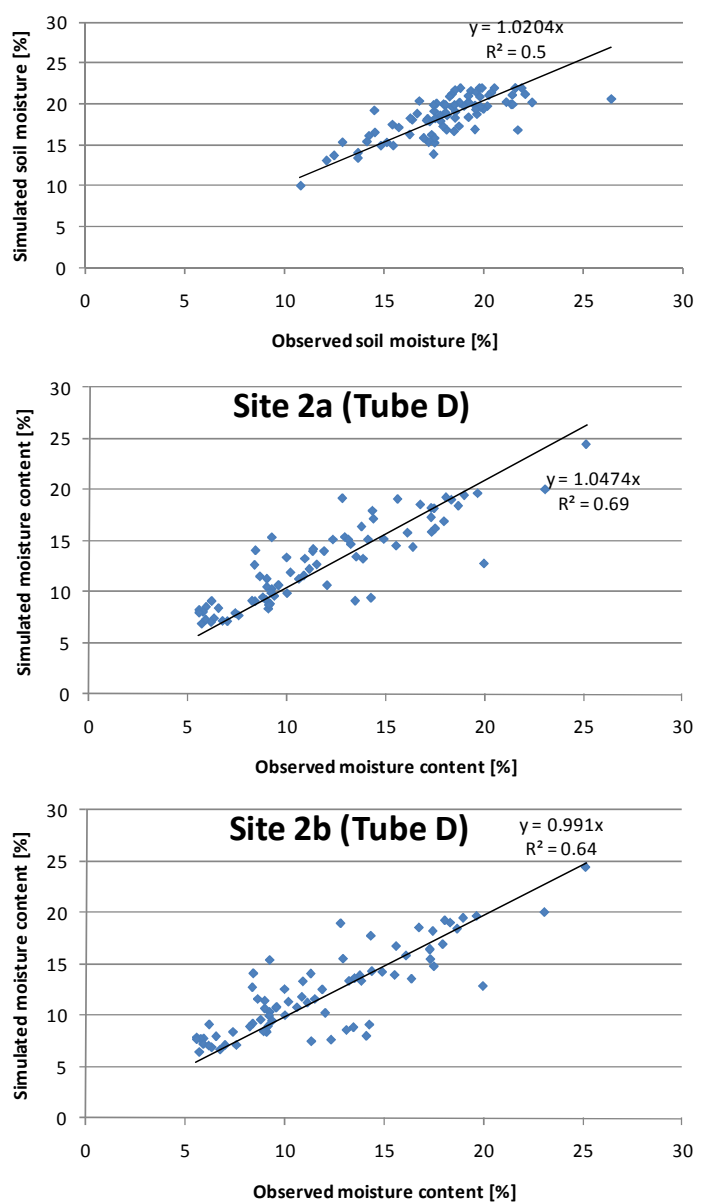

Fig. 5. Comparison of observed and modelled moisture in Tube A (control) and Tube D.

\subsubsection{Sensitivity analysis}

A sensitivity analysis has been conducted to check if the assumed values for some parameters used in the model would have any significant influence on model output. Assumptions were made for $p$ (soil moisture depletion factor), $k$ (residence time of water within soil profile above field capacity), $D$ (Interception threshold), $k_{c}$ (crop coefficients) and $k_{p}$ (pan factor).

$k_{c}$ and $k_{p}$ values are obtained from standard guidelines. Also $p$ is not likely to vary much away from the generally recommended value of 0.6. These parameters result in minimum sensitivity within reasonable ranges as offered in standard guidelines. $k_{R}$ (residence time above field capacity) does not affect the daily water balance as, in the model, this retention time does not exceed 1.5 days. This only leaves the interception threshold as an important parameter to be tested in a sensitivity analysis. $D$ ranges between $2-5 \mathrm{~mm} \mathrm{~d}^{-1}$ (after De Groen and Savenije, 2006).
The sensitivity analysis shows that $D$ is not a sensitive parameter for the calculation of transpiration values. Figure 6 shows graphs of total seasonal transpiration obtained for interception values ranging between $1-5 \mathrm{~mm} \mathrm{~d}^{-1}$, and a comparison of the values with the $3 \mathrm{~mm} \mathrm{~d}^{-1}$ interception threshold used in the model. Seasonal transpiration for $D$ values of 1,3 and $5 \mathrm{~mm} \mathrm{~d}^{-1}(D 1, D 3$ and $D 5$, respectively) are plotted against the value used in the model, $D 3$ (i.e. a change in $D$ $(d D / D)$ of $67 \%)$. This change in $D$ would result in change in transpiration of $d T / T$.

The deviation from the $D 3$ graph is less than $20 \%$ in all cases (see Fig. 6). The sensitivity of the relationship can be expressed as an elasticity relationship $[(d T / T) /(d D / D)]$ where an elasticity of 1 reflects a highly sensitive relationship. In most cases, an inelastic relationship of less than 0.3 is obtained which confirms that $D$ is not a very sensitive parameter. While the interception threshold does not prove to be a sensitive parameter, interception is still important in water balance analysis as the available water for other processes (e.g. transpiration) is dependent on the balance available after interception. 
Site 3 with diversions
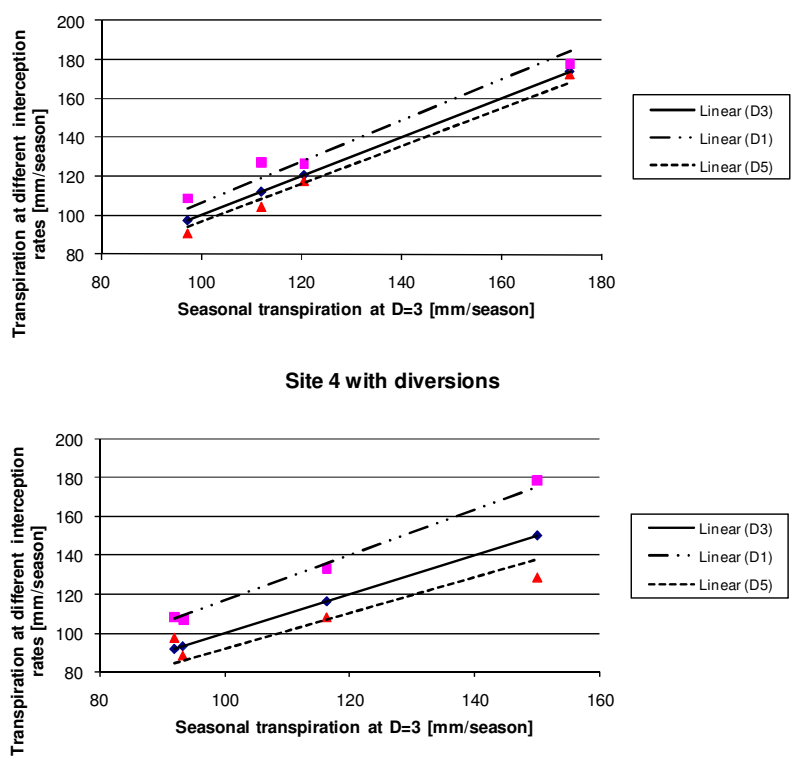

Site 3 without diversions
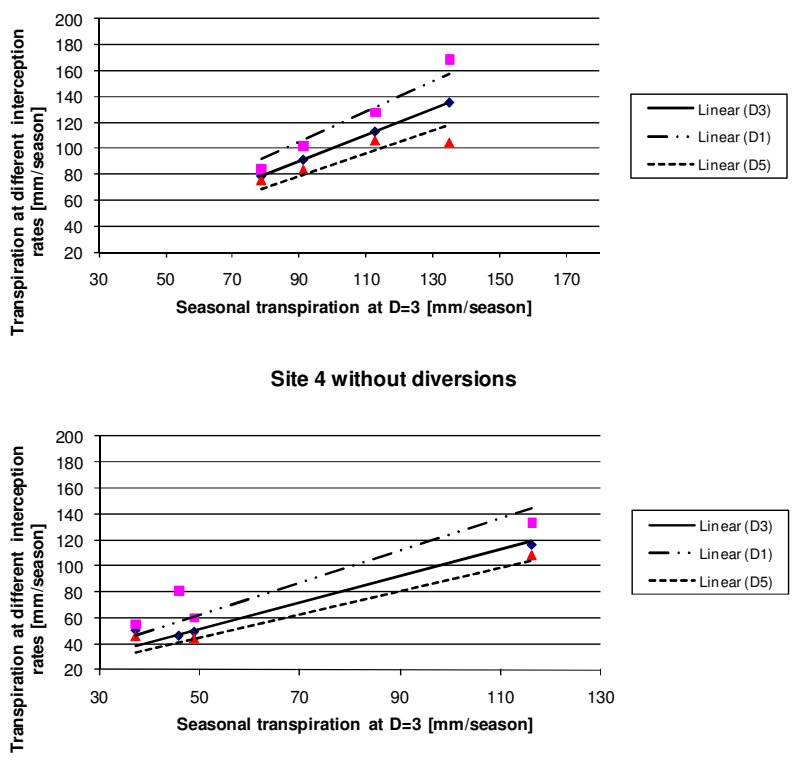

Fig. 6. Comparison of seasonal transpiration values for different interception thresholds.

\subsection{Water balances}

The total amount of water received at field scale is due to the rainfall $(P)$ and runoff diversion $\left(Q_{s}\right)$. This water is partitioned into transpiration $\left(E_{T}\right)$, interception $\left(E_{I}\right)$, soil evaporation $\left(E_{S}\right)$, deep percolation $(R)$ and soil moisture storage variation $\left(d S_{u} / d t\right)$.

Table 1 shows the average daily water partitioning for the combined cropping seasons. At Site 1, the volume of water diverted surpasses the rainfall received while at Site 2, the runoff contribution is about $30 \%$ of rainfall received. Deep percolation accounts for the largest proportion of the partitioned water.

For the combined seasons, at Site1, transpiration increased from an average of $1 \mathrm{~mm} \mathrm{~d}^{-1}$ to $1.4 \mathrm{~mm} \mathrm{~d}^{-1}$ (range 0.86 $1.93 \mathrm{~mm} \mathrm{~d}^{-1}$ ) as a result of the improved agricultural techniques. At Site 2, the average transpiration increased from $0.7 \mathrm{~mm} \mathrm{~d}^{-1}$ to $1.1 \mathrm{~mm} \mathrm{~d}^{-1}$ (range $0.37-1.26 \mathrm{~mm} \mathrm{~d}^{-1}$ ). Despite an increase in transpiration values, deep percolation accounts for almost $50 \%$ of the diverted water at both sites.

\section{Analysis and discussion of results}

Simulation results show that the SIs result in increased moisture availability in the study plots and, hence, confirm that there is, indeed, scope for improved productivity if dry spell management is improved. More moisture in the root zone leads to increased potential for transpiration and, hence, biomass production. The lower moisture levels in the control section can be explained by the fact that the control section, because it is entirely rainfed, has less water available to infiltrate. The traditional cultivation technique of using the hand hoe results in the formation of a hard pan thus reducing the infiltration potential while increasing the potential for soil evaporation (Rockström et al., 2001). On the other hand, the trenches improve the potential for infiltration through increased residence time in the field. In the section with the SIs, the moisture distribution varies across the field in response to the impacts of the SIs. The highest soil moisture levels are observed near the soil bunds (around Tube D) where more residence time for water enhances infiltration. This ponding effect also increases the chances of deposition of nutrient-rich fine sediment which also benefits the crop. The difference in moisture levels at Tubes B, C and D can further be attributed to the effect of soil depth and slope. At Site 1, where the slope is flatter and the soils are deeper, more infiltration and vertical drainage occurred resulting in the tube next to the trench (Tube B) not responding as much to the diversion as at Site 2. At Site 2 the middle tube, Tube $\mathrm{C}$, recorded soil moisture values which are similar to the control tube suggesting that the moisture that infiltrates in the fanya juu trenches does not reach the centre of the plot through lateral drainage, but is evacuated vertically as subsurface drainage. This suggests that, for the fanya juu technique to be more effective on steeper terrains, the spacing between trenches should be further reduced to values much less than those recommended for soil conservation. A 2-D model such as HYDRUS2/3D would better explain this process.

The model results also show the positive effects of diverting runoff onto the field plots. The additional water available through diversions and the subsequent temporary in-field 
Table 1. Water partitioning "with" and "without" Sis (mm d-1).

\begin{tabular}{lccccccccc}
\hline & $P$ & $Q_{S}$ & Total inflows & $E_{T}$ & $E_{I}$ & $E_{S}$ & $R_{g}$ & $\frac{d S_{u}}{d t}$ & Total outflows \\
\hline Site 3 & & & & & & & & & \\
with & 2.1 & 2.7 & 4.8 & 1.4 & 0.7 & 0.2 & 2.3 & 0.2 & 4.8 \\
without & 2.1 & 0 & 2.1 & 1.0 & 0.7 & 0.1 & 0.2 & 0.1 & 2.1 \\
Site 4 & & & & & & & & & \\
with & 2.8 & 1.0 & 3.8 & 1.1 & 0.7 & 0.2 & 1.6 & 0.2 & 3.8 \\
without & 2.8 & 0 & 2.8 & 0.7 & 0.7 & 0.2 & 1.0 & 0.2 & 2.8 \\
\hline
\end{tabular}

storage of water facilitates the attainment of conducive moisture levels for germination in a relatively shorter time than without the SIs. This effectively lengthens the growing season with the crop benefitting more from the available water in a season. This means that crops grown under the adjusted farming conditions, in addition to benefitting from a longer growing season, also stand a less chance of suffering from moisture stress during dry spells and, hence, are likely to obtain higher yields compared to those crops grown under traditional practices. Grain yield increases of more than threefold have been recorded under these improved farming systems (Makurira et al., 2010). At Site 1, the difference in moisture availability between control conditions and those under SIs is much larger than at Site 2 due to the fact that the diversion potential is much higher at Site 1 and, also, the gentler slope at Site 1 promotes more water retention and infiltration than at Site 2.

The moisture gap during dry seasons between the control and the locations benefitting from diversions in the dry season suggests that residual moisture is higher under the new technique, thus allowing for the cultivation of alternative crops in the dry season, particularly around the trenches and bunds. These dry season crops have proved a success and provide alternative cropping practices and additional food in the dry season.

The water partitioning analysis shows that the effect of the diversion is also a function of slope and soil depth. Steeper slopes experience less infiltration. In such cases more surface runoff leaves the system as lateral flow. Diversions increase in-field water availability which, depending on the partitioning processes, should result in more water available for productive purposes. The proportion of water attributed to deep percolation also demonstrates that the available water with SIs cannot all be retained within the root zone during the short rainfall events. This suggests that the trenches do not offer sufficient storage to regulate the release of water into the root zone when required. Rockström et al. (2001) also showed that non-productive purposes (evaporation and deep percolation) can easily account for more than $50 \%$ of the available water. Re-partitioning of available water to increase productivity should therefore not only focus on reducing evaporation processes but should also aim to restrict the infiltrated water to the root zone only through, e.g. construction of micro-storages from where water can be released only when required.

\section{Conclusions}

With rainfall of less than $400 \mathrm{~mm} / \mathrm{season}$ it is very clear that rainfall alone is not sufficient to support common food crops (e.g. maize) in the study area. The existing cultivation techniques are not efficient enough to cope with the frequent dry spells hence the need to apply more efficient farming techniques. The SIs tested in this research i.e. fanya juus used in combination with storm water diversion, have demonstrated the potential to improve the soil moisture availability within cultivated plots and, hence, increase the transpiration potential.

Modelling techniques have been applied successfully to complement observed data. It has been shown that the major advantages of the tested techniques are that the growing season effectively starts earlier while the damage due to mid season dry spells is minimised by the generally higher soil moisture conditions created. It has also been demonstrated that the ponding zones created around the bunds offer wetter and, possibly, more fertile conditions for crop growth. Where shallower soils exist, especially in combination with steeper slopes, the findings show that the water in the trenches drains more as sub-surface lateral flow which may not benefit the root zone. Since the trenches and bunds are constructed according to soil conservation guidelines, this then may suggest that, in steeper slopes and for the fanya juи structures to be more effective, the spacing between the bunds and the trenches should be less than that recommended for soil conservation purposes. The HYDRUS2D model has been used to demonstrate this process in a paper being prepared by the authors.

The tested techniques show that higher moisture levels are obtained even in the dry seasons. This is an advantage in that longer season alternative crops (such as bananas, pawpaws, fodder and cassava) can be successfully grown in the trenches and at the bunds. However, the general decline in soil moisture levels throughout the dry season as a result of soil evaporation implies that valuable soil moisture 
is lost through soil evaporation during the dry seasons. If conserved, the moisture level at the close of the growing season could provide a better starting point at the beginning of the subsequent season. Therefore, a way of minimising dry season evaporation can significantly benefit the performance of the subsequent season. Future research should focus on investigating different land management techniques (e.g. different ploughing techniques, or reducing bare soil evaporation by introducing a canopy, Wallace et al., 1999) to reduce moisture losses through soil evaporation during the dry seasons.

The high proportion of water entering the deep percolation zone suggests that there is still inefficient utilisation of harvested water even under the tested SI systems. In hydrological terms this is not a loss as this water would most likely benefit downstream ecosystems. However, at local scales, this demonstrates that the in-field temporary storages created, while they help in altering the water balance, cannot cope with the generated volumes of water and do not allow for regulated release of water into the root zone when required. The tested techniques would most likely perform more efficiently when used in combination with (micro) storage systems for more effective dry spell management. Future investigation should therefore focus on SIs in combination with micro dams and/or storage tanks from rainwater harvesting.

Acknowledgements. The work reported here was undertaken as part of the Smallholder System Innovations in Integrated Watershed Management (SSI) Programme funded by the Netherlands Foundation for the Advancement of Tropical Research (WOTRO), the Swedish International Development Cooperation Agency (SIDA), the Netherlands Directorate-General of Development Cooperation (DGIS), the International Water Management Institute (IWMI) and UNESCO-IHE Institute for Water Education. The Soil and Water Management Research Group (SWMRG) of the, Sokoine University of Agriculture in, Tanzania assisted implementation on site.

Edited by: E. Zehe

\section{References}

Allen, R., Pereira, L., Smith, M., Raes, D., and Wright, J.: Crop Evapotranspiration: Guidelines for computing crop water requirements, FAO Irrig. Drain. Paper, 56, 1998.

Allen, R., Pereira, L., Smith, M., Raes, D., and Wright, J.: FAO-56 Dual Crop Coefficient Method for Estimating Evaporation from Soil and Application Extensions, J. Irrig. Drain. E.-ASCE, 2005.

Allen, R. G.: Using the FAO-56 dual crop coefficient method over an irrigated region as part of evapotranspiration intercomparison study, J. Hydrol., 22(229), 27-41, 2000.

Barron, J., Rockström, J., Gichuki, F., and Hatibu, N.: Dry spell analysis and maize yields for two semi-arid locations in East Africa, Agr. Forest Meteorol., 117, 23-37, 2003.
Bhatt, Y., Bossio, D., Enfors, E., Gordon, L., Kongo, V., Kosgei, J. R., Makurira, H., Masuki, K., Mul, M., and Tumbo, S. D.: Smallholder System Innovations in Integrated Watershed Management (SSI): Strategies of water for food and environmental security in drought-prone tropical agro-ecosystems. Colombo, Sri Lanka: International Water Management Institute, IWMI working paper 1009; SSI Working Paper 1, 59 pp., 2006

De Groen, M. M. and Savenije, H. H. G.: A monthly interception equation based on the statistical characteristics of daily rainfall, Water Resour. Res., 42, W12417, doi:10.1029/2006WR005013, 2006.

Decagon Devices Inc.: AccuPar PAR/LAI ceptometer, Model LP80: Operators Manual, Version 1.2., 2004.

Enfors, E. and Gordon, L.: Analyzing resilience in dryland agroecosystems, A case study of the Makanya catchment in Tanzania over the past 50 years, Land degradation and development, 18, 680-696, 2007.

Enfors, E. and Gordon, L.: Dealing with drought: The challenge of using water system technologies to break dryland poverty traps, Global Environ. Chang., 18(4), 607-616, 2008.

Fischer, B. M. C.: Spatial variability of dry spells, a spatial and temporal rainfall analysis of the Pangani Basin \& Makanya catchment, Tanzania, MSc Thesis, Delft University of Technology, Delft, 2008.

Gichuki, F.: Mokueni District Profile: Soil Management and Conservation, Drylands Research, Working Paper 4., 2000.

Kosgei, J. R.: Rainwater harvesting systems and their influences on field scale soil hydraulic properties, water fluxes and crop production in Potshini catchment, South Africa, PhD Thesis, University of KwaZulu-Natal, South Africa, 2009.

Makurira, H., Savenije, H., Uhlenbrook, S., Rockström, J., and Senzanje, A.: The effect of improved on-farm techniques on maize yield and water productivity in sub-Saharan rainfed agricultural systems, Journal of Agricultural Water Management, in review, 2010.

Mul, M. L., Mutiibwa, R. K., Foppen, J. W. A., Uhlenbrook, S., and Savenije, H. H. G.: Identification of groundwater flow systems using geological mapping and chemical spring analysis in South Pare Mountains, Tanzania, Phys. Chem. Earth, 32(15-18), 10151022, 2007.

Mul, M. L., Savenije, H. H. G., and Uhlenbrook, S.: Spatial rainfall variability and runoff response during an extreme event in a semiarid catchment in the South Pare Mountains, Tanzania, Hydrol. Earth Syst. Sci., 13, 1659-1670, 2009, http://www.hydrol-earth-syst-sci.net/13/1659/2009/.

Mupangwa, W., Love, D., and Twomlow, S.: Soil water conservation and rainwater harvesting strategies in the semi arid Mzingwane Catchment, Limpopo Basin, Zimbabwe. Phys. Chem. Earth, 31, 893-900, 2006.

Mutiro, J., Makurira, H., Senzanje, A., and Mul, M. L.: Water productivity analysis for smallholder rainfed systems: A case study of Makanya catchment, Tanzania, Phys. Chem. Earth, 31(15-16), 901-909, 2006.

Mwangi, J. N., Mboya, T. O. and Kihumba, J.: Improved maize production in Central Kenya with adoption of soil and water conservation measures, Proceedings of the 7th Eastern and Southern African Regional Maize Conference, 299-300, 2001. 
Ngigi, S. N. (Ed.): Rainwater Harvesting for Improved Food Security. Promising Technologies in the Great Horn of Africa, Greater Horn of Africa Partnerships, Kenya Rainwater Association, 2003.

Ngigi, S. N., Savenije, H. H. G., and Gichuki, F. N.: Land use changes and hydrological impacts related to up-scaling of rainwater harvesting and management in upper Ewaso $\mathrm{Ng}$ 'iro river basin, Kenya, Land Use Policy, 24, 129-140, 2007.

Ngigi, S. N., Savenije, H. H. G., Thome, J. N., Rockström, J., and de Vries, F. W. T. P: Agro-hydrological evaluation of on-farm rainwater storage systems for supplemental irrigation in Laikipia district, Kenya, Agr. Water Manage., 73, 21-41, 2005.

Novák, V., Hurtalová, T., and Matejka, F.: Predicting the effects of soil water content and soil water potential on transpiration of maize, Agr. Water Manage., 76, 211-223, 2005.

Rockström, J.: Water resources management in smallholder farms in eastern and southern Africa: An overview, Phys. Chem. Earth, 25(3), 275-283, 2000.

Rockström, J.: Green water security for the food makers of tomorrow: windows of opportunity in drought-prone savannahs, Water Sci. Technol., 43(4), 71-78, 2001.

Rockström, J.: Water for food and nature in drought-prone tropics: vapour shift in rainfed agriculture, The Royal Society, 19972009, 2003.
Rockström, J., Folke, C., Gordon, L., Hatibu, N., Jewitt, G., de Vries, F. P., Rwehumbiza, F., Sally, H., Savenije, H., and Schulze, R.: A watershed approach to upgrade rainfed agriculture in water scarce regions through Water System Innovations: an integrated research initiative on water for food and rural livelihoods in balance with ecosystem functions, Phys. Chem. Earth, 29(15-18), 1109-1118, 2004.

Rockström, J., Kaumbutho, P., Mwalley, P., and Temesgen, M.: Conservation farming among smallholder farmers in E.Africa: Adapting and adopting innovative land management options, 1st World Congress on Conservation Agriculture, 363-373, 2001.

Savenije, H. H. G.: Determination of evaporation from a catchment water balance at a monthly time scale, Hydrol. Earth Syst. Sci., 1, 93-100, 1997, http://www.hydrol-earth-syst-sci.net/1/93/1997/.

Temesgen, M., Rockstrom, J., Savenije, H. H. G., and Hoogmoed, W. B.: Assessment of strip tillage systems for maize production in semi-arid Ethiopia: effects on grain yield and water balance, Hydrol. Earth Syst. Sci. Discuss., 4, 2229-2271, 2007, http://www.hydrol-earth-syst-sci-discuss.net/4/2229/2007/.

Tenge, A. J. M., De Graaff, J., and Hella, J. P.: Financial efficiency of major soil and water conservation measures in West Usambara highlands, Tanzania, Appl. Geogr., 25, 348-366, 2005.

Wallace, J. S., Jackson, N. A., and Ong, C. K.: Modelling soil evaporation in an agroforestry system in Kenya, Agr. Forest. Meteorol., 94, 189-202, 1999. 